\title{
Spontaneous tyrosinase mutations identified in albinos of three wild frog species
}

\author{
Ikuo Miura $^{1 *}$, Masataka Tagami ${ }^{2}$, Takeshi Fujitani ${ }^{3}$ and Mitsuaki Ogata ${ }^{4}$ \\ ${ }^{1}$ Amphibian Research Center, Hiroshima University, 1-3-1 Kagamiyama, Higashi-Hiroshima, Hiroshima 739-8526, \\ Japan \\ ${ }^{2}$ Gifu World Freshwater Aquarium, 1453 Kawashima-Kasadamachi, Kakamigahara, Gifu 501-6021, Japan \\ ${ }^{3}$ Higashiyama Zoo and Botanical Gardens Information, 3-70 Higashiyama-Motomachi, \\ Chikusa-ku, Nagoya, Aichi 464-0804, Japan \\ ${ }^{4}$ Preservation and Research Center, The City of Yokohama, 155-1 Kawaijuku-cho \\ Asahi-ku, Yokohama, Kanagawa 241-0804, Japan
}

(Received 1 November 2016, accepted 9 March 2017; J-STAGE Advance published date: 30 June 2017)

The present study reports spontaneous tyrosinase gene mutations identified in oculocutaneous albinos of three Japanese wild frog species, Pelophylax nigromaculatus, Glandirana rugosa and Fejervarya kawamurai. This represents the first molecular analyses of albinic phenotypes in frogs. Albinos of $P$. nigromaculatus collected from two different populations were found to suffer from frameshift mutations. These mutations were caused by the insertion of a thymine residue within each of exons 1 and 4, while albinos in a third population lacked three nucleotides encoding lysine in exon 1. Albinos from the former two $P$. nigromaculatus populations were also associated with splicing variants of mRNA that lacked either exons 2-4 or exon 4. In the other two frog species examined, missense mutations that resulted in amino acid substitutions from glycine to arginine and glycine to aspartic acid were identified in exons 1 and 3, respectively. The two glycines in $F$. kawamurai and G. rugosa, and the lysine deleted in one $P$. nigromaculatus albino, were highly conserved in vertebrates, which suggested that they were situated in regions of critical importance to tyrosinase function. In fact, the glycine of $G$. rugosa is located within a predicted copperbinding domain. The five mutations identified in the present study are candidates for causing the albinic phenotypes, and, if directly confirmed, they are all unique among vertebrates, which suggests that molecular analysis of albino frogs could contribute to research on albinos in humans and vertebrates by providing new information about tyrosinase structure and transcript processing.

Key words: albino, tyrosinase, mutation, frog, mRNA isoform

\section{INTRODUCTION}

The external coloration of organisms plays important roles in biological functions such as adaptation to the environment, reproduction and speciation. Coloration is expressed as a result of color pigments and their cumulative effects in cells in skin, feathers and hair. The biosynthesis of melanin, a major color pigment deposited in melanocytes that is mainly black or brown, relies heavily on tyrosinase, an enzyme that catalyzes two steps in the pathway that produces melanin. Amelanotic phenotypes are caused by mutations in the tyrosinase

Edited by Kiichi Fukui

* Corresponding author. E-mail: imiura@hiroshima-u.ac.jp

DOI: http://doi.org/10.1266/ggs.16-00061 gene. In humans, tyrosinase has been extensively studied due to its applications in both medical and cosmetic sciences. The amino acid and nucleotide sequences of the tyrosinase gene in vertebrates were first determined in mice (Yamamoto et al., 1987; Müller et al., 1988) and humans (Kwan et al., 1987). Since then, the tyrosinase gene in humans has been associated with 265 cases of oculocutaneous albinism type 1 (OCA1), all of which have been analyzed and their causative mutations identified (http://www.ifpcs.org/albinism/).

In amphibians, external coloration is directly expressed by pigment cells in the skin. This is thus highly advantageous for researching coloration and has led to extensive examination of amphibian coloration in the twentieth century (Bagnara et al., 1968). Since some Japanese frog species breed in paddy fields and ponds that are located in 
close proximity to humans, unusual coloration of tadpoles, including albinic phenotypes, can easily be detected and is frequently reported. Indeed, many cases of color variation in Japanese tadpoles are reported each year (Miura, 2009; Teraoka and Yamaguchi, 2009; Teraoka, 2013). In previous studies involving the Japanese frog Pelophylax nigromaculatus, 13 different kinds of albinos were collected from wild populations, stored, and classified based on five distinct loci, one of which was postulated to encode tyrosinase and produce the completely amelanotic phenotype, with pinkish eyes and yellow skin where no melanotic cells, and no deformities in the other two pigment cells of xanthophore and iridophore, are visible (Nishioka and Ueda, 1985; Nishioka et al., 1987). Sequences of tyrosinase cDNA and its associated genomic region were determined in the wild-type frog of the species (Takase et al., 1992; Miura et al., 1995). Despite these fortuitous conditions, molecular analysis of albino frogs has not previously been undertaken.

In the present study, two questions regarding albinism in frogs are examined. First, are the associated caus- ative tyrosinase mutations species- or amphibian-specific, or do they also occur in humans? Second, does albinism in frogs of the same species taken from different localities share the same origin, or did albinism arise independently in different populations? To investigate these questions, the sequences of tyrosinase genes from albinos showing a completely amelanotic phenotype in three different frog species were determined, with individuals of one species having been collected from three different localities. The mutations identified in the present study were all unique among vertebrates.

\section{MATERIALS AND METHODS}

Albino frogs and pigment cell observation All the albinos examined in the present study were collected from the wild when they were tadpoles, and were then reared at facilities of Hiroshima University or Gifu World Freshwater Aquarium (Fig. 1). Albinic tadpoles of Pelophylax nigromaculatus, $\mathrm{A}^{\mathrm{K}}, \mathrm{A}^{\mathrm{I}}$ and $\mathrm{A}^{\mathrm{H}}$, were collected from Kumamoto city, Kumamoto prefecture in 2013 (by Kikuo
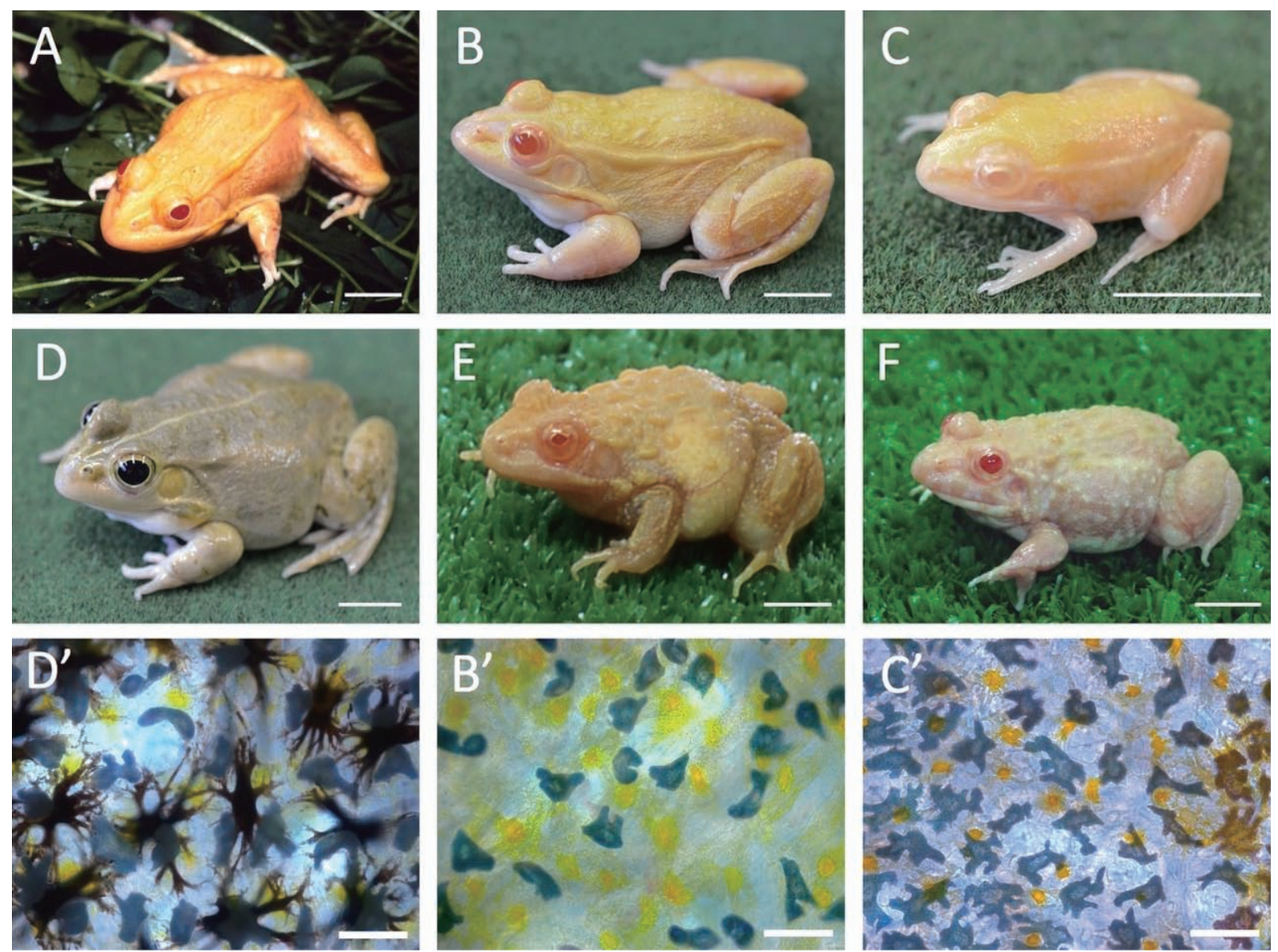

Fig. 1. External morphology and pigment cells of albino frog specimens. Albinos of Pelophylax nigromaculatus (A, B, C) from Kure city, Hiro-machi $\left(\mathrm{A}^{\mathrm{H}}\right)$, Kumamoto $\left(\mathrm{A}^{\mathrm{K}}\right)$ and Ichinomiya $\left(\mathrm{A}^{\mathrm{I}}\right)$ cities; wild-type frog of P. nigromaculatus (D); and albinos of Glandirana rugosa (E) and Fejervarya kawamurai (F). Pigment cells in the skin of wild-type and albino frogs of $\mathrm{A}^{\mathrm{K}}$ and $\mathrm{A}^{\mathrm{I}}(P$. nigromaculatus) (D', B' and C'). Bar indicates $1 \mathrm{~cm}$ in $\mathrm{A}-\mathrm{F}$ and $50 \mu \mathrm{m}$ in D', B' and C'. 
Matsumi), Ichinomiya city, Aichi prefecture in 2015 and Kure city (Hiro-machi), Hiroshima prefecture in 1979, respectively. Albinic tadpoles of Glandirana rugosa and Fejervarya kawamurai were collected from Miyoshi city, Hiroshima prefecture in 2000 (by Yoshiharu Takeyasu) and Yukuhashi city, Fukuoka prefecture in 2002 (by Manji Yamamoto), respectively. We used a heterozygous frog of $F$. kawamurai, which was an offspring from a cross of the albino with a wild-type frog, for molecular analysis in this study. For observation of pigment cells, a small piece of skin that was taken from the dorsal surface of a frog after low-temperature anesthesia in iced water was put on a glass slide in Amphibian Ringer solution with a coverslip, and observed under a microscope (Nikon Eclipse 80i/ Plan Fluor, DS-US/DS-Ri1 camera). Animal care and experimental procedures were conducted under approval of the Committee for Ethics in Animal Experimentation at Hiroshima University (Permit Number: G13-3).

Genomic Southern blot hybridization This hybrid-
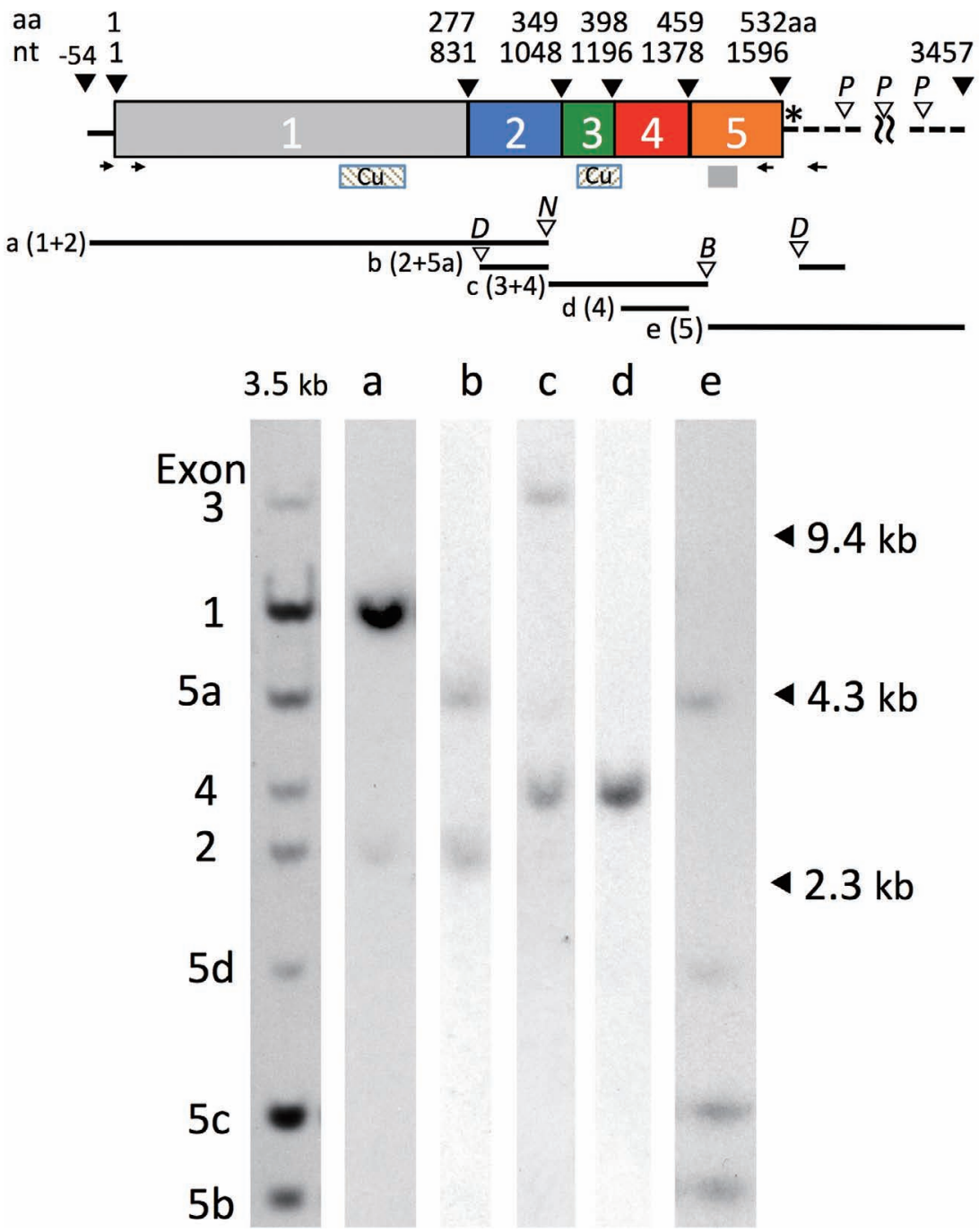

Fig. 2. Genomic Southern blot hybridization of the tyrosinase gene in Pelophylax nigromaculatus. The exon structure of tyrosinase cDNA is shown at the top. DNA fragments (3.5 kb and a-e) used to construct probes are shown in the middle (numbers in parentheses indicate exons). Results of hybridization are shown at the bottom. aa, amino acid sequence; nt, nucleotide sequence. Three PstI sites located within the untranslated region (part of exon 5) divide exon 5 into four parts (5a-d). Restriction sites (P, PstI; D, DdeI; B, BglII; N, NcoI) are indicated by open triangles. Closed triangles indicate 5' and 3' ends of cDNA as well as the ends of the five exons. Two predicted copper-binding domains (aa 184-214 and 367-394) are indicated by hatched rectangles, and a transmembrane domain (aa 479-499) by the gray rectangle, under the exon structure. The locations of primers used for amplifying tyrosinase cDNA fragments are shown by arrows; those used for F. kawamurai are located within exons 1 and 5 (see text for the precise nucleotide numbers). Asterisk indicates the stop codon. Size markers are shown to the right of lane (e). 
ization was performed according to the method of Miura et al. (1998). DNA (15 $\mu \mathrm{g})$ cut with PstI was electrophoresed in a $0.8 \%$ agarose gel and then transferred to a nylon membrane in $10 \times \mathrm{SSC}(1.5 \mathrm{M} \mathrm{NaCl}$ and $0.17 \mathrm{M}$ sodium citrate) after denaturation with $0.5 \mathrm{M} \mathrm{NaOH}$ and $1.5 \mathrm{M} \mathrm{NaCl}$ followed by neutralization with $0.5 \mathrm{M}$ Tris and $1.5 \mathrm{M} \mathrm{NaCl}$ ( $\mathrm{pH} 7.5$ ), and hybridized with digoxigenin-labeled probe in $0.05 \mathrm{M}$ sodium phosphate buffer containing $5 \times \mathrm{SSC}, 10 \% \mathrm{SDS}, 2 \%$ blocking solution, $0.1 \%$ $\mathrm{N}$-lauroylsarcosine and denatured salmon sperm DNA $(60 \mu \mathrm{g} / \mathrm{ml})$ at $68{ }^{\circ} \mathrm{C}$ for $16 \mathrm{~h}$. The membrane was washed three times in $2 \times \mathrm{SSC}, 0.1 \% \mathrm{SDS}$ at room temperature for $5 \mathrm{~min}$ and once in $0.1 \times \mathrm{SSC}, 0.1 \% \mathrm{SDS}$ at $68{ }^{\circ} \mathrm{C}$ for $30 \mathrm{~min}$, and then exposed to X-ray film after immersion in anti-digoxigenin-AP conjugate (1:10,000), washing, and incubation with 1/100 CSPD (Roche). The DNA fragments used for probes were as follows (Fig. 2): the full-length cDNA fragment $(3,511 \mathrm{bp})$, an NcoI fragment corresponding to exons 1 and $2(1,058 \mathrm{bp})$, an NcoI + BglII fragment corresponding to exons 3 and 4 (421 bp), an 800-bp genomic fragment of exon 4 including parts of introns 3 and 4, DdeI + NcoI and DdeI + PstI fragments (140 bp and $142 \mathrm{bp}$, respectively) corresponding to exons 2 and part of exon 5 (5a), and a BglII fragment corresponding to exon 5 (2,034 bp).

Amplification of tyrosinase cDNA and genomic regions Total RNA and genomic DNA were extracted from a small piece of skin, which was taken from the dorsal surface of a frog after low-temperature anesthesia in iced water. The piece of skin was crushed with a plastic pestle, and RNA and DNA were then separately extracted using a NucleoSpin TriPrep kit (Takara) according to the manufacturer's instructions. cDNA was synthesized from $0.2-1 \mu \mathrm{g}$ of total RNA using a Verso cDNA Synthesis Kit (Thermo Fisher Scientific) in $20 \mu$ reaction buffer containing $4 \mu \mathrm{l}$ of $5 \times$ reaction buffer, $1 \mu \mathrm{l}$ of $\mathrm{dT}_{24}$ oligomer, $2 \mu \mathrm{l}$ of $10 \mathrm{mM}$ dNTP, $1 \mu \mathrm{l}$ of RNase inhibitor and 1 $\mu \mathrm{l}$ of reverse transcriptase at $55^{\circ} \mathrm{C}$ for $50 \mathrm{~min}$ and ending at $80{ }^{\circ} \mathrm{C}$ for $15 \mathrm{~min}$.

Tyrosinase cDNA and genomic DNA fragments were amplified using PrimeSTAR GXL DNA Polymerase (Takara): $0.5 \mu \mathrm{l}$ of cDNA or DNA was amplified in $25 \mu \mathrm{l}$ reaction solution containing $0.5 \mu \mathrm{l}$ of GXL DNA polymerase, $5 \mu \mathrm{l}$ of $5 \times$ buffer solution, $4 \mu \mathrm{l}$ of dNTP and $0.5 \mu \mathrm{l}$ of each of the $12.5 \mu \mathrm{M}$ primers for 40 cycles at $98^{\circ} \mathrm{C}$ for $10 \mathrm{~s}, 55^{\circ} \mathrm{C}$ for $10 \mathrm{~s}$ and $68^{\circ} \mathrm{C}$ for $1-3 \mathrm{~min}$ with a Life Eco thermal cycler (Nippon Genetics). The amplified products were electrophoresed on a $6 \%$ polyacrylamide gel with $1 \times$ TAE running buffer, or purified using a FastGene Gel/PCR Extraction Kit (Nippon Genetics) and cloned into pUC118 using the Mighty cloning reagent set (Takara) for sequence analysis. The nucleotide sequence was determined with ABI PRISM 3130 XL genetic analyzer (Applied Biosystems) according to the manufactur- er's instruction. The primers used for amplification of tyrosinase cDNA were as follows: cDNA forward 5'-GAG GTC TGA GGA GGA TCA CTA GG-3' and reverse 5'-GGA TCG TAG AGT AAT TTC CCA GAG-3' for P. nigromaculatus and G. rugosa; and forward 5'-CTC YTR AGC AAG GAR TGT TGC CC-3' and reverse 5'-TGR TAR TCT TCR GCY TCC ATG AG-3' for F. kawamurai. The primers used for amplification of tyrosinase genomic regions were as follows: exon1 forward 5'-AGT GCA GGT TTG GCT ACA CA-3'and reverse 5'-TGG GCC CCA GAT AGC AGT AA-3' for $P$. nigromaculatus; cDNA forward primer and reverse 5'-GCG AAC ATS GGA TTG GAG CC-3' for $F$. kawamurai; exon 3 forward 5'-GGG TAT GCT GTT CCA TCC TC-3' and reverse 5'-TC ACG AAC GCA TGA TGA AGA-3' for P. nigromaculatus; and exon 4 forward 5'-ATG TCC CTG ATG GCA CTT CC-3' and reverse 5'AGC CAC ATG AAA AGC CCA TC-3' for P. nigromaculatus. The nucleotide sequences of tyrosinase cDNA from wild-type frogs of $G$. rugosa and $F$. kawamurai are available in the DDJB/EMBL/GenBank databases under accession numbers LC146645 and LC146646.

\section{RESULTS}

External morphology of albinos The albinic frogs examined in the present study are shown in Fig. 1. Their dorsal skin coloration was predominantly yellowish, while their eyes were pinkish (Fig. 1A-C, E and F). In the skin of albinic $P$. nigromaculatus, pigment cells that were normally observed in wild-type frogs (Fig. 1D and D'), such as melanocytes, were not detected (Fig. 1B' and C'); however, no anomalous pigmentation was detected in xanthophores or iridophores located in either the skin or the iris.

Exon structure In humans, mice and fish, tyrosinase genes are commonly made up of five exons (Giebel et al., 1991; Inagaki et al., 1998; Ruppert et al., 1988). In the frog $P$. nigromaculatus, exons 1, 4 and 5 were successfully identified through genomic cloning, while exons 2 and 3 were not. Exons 2 and 3 were presumed to exist based

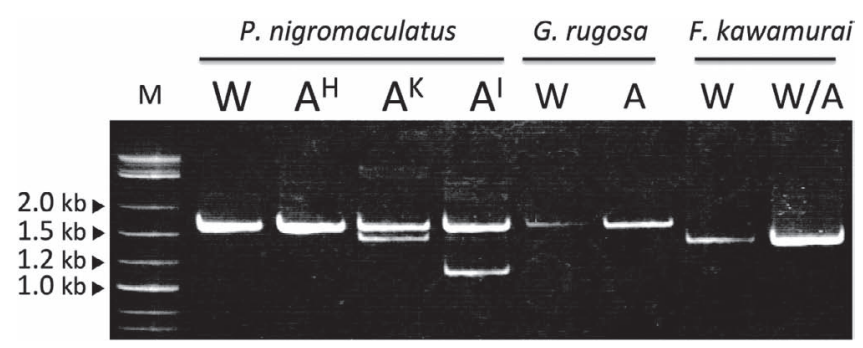

Fig. 3. Amplified fragments of tyrosinase cDNA from albino and wild-type frogs of three species. W and A indicate wild-type and albinic frogs, respectively. Abbreviations are the same as in Fig. 1. A shorter, extra cDNA fragment was amplified along with the normal-sized fragment in $\mathrm{A}^{\mathrm{K}}$ and $\mathrm{A}^{\mathrm{I}}$ albinos. Size markers are shown next to the leftmost lane (M). 
on conserved donor and acceptor sequences for exonintron splice junctions in the cDNA sequence (Takase et al., 1992; Miura et al., 1995). Based on this information, genomic Southern blot analysis was used to confirm the exon structure of the tyrosinase gene in the frog species. Using frog tyrosinase cDNA with a total length of $3.5 \mathrm{~kb}$ (this length includes three PstI sites within the untranslated region of exon 5) as a probe, eight bands
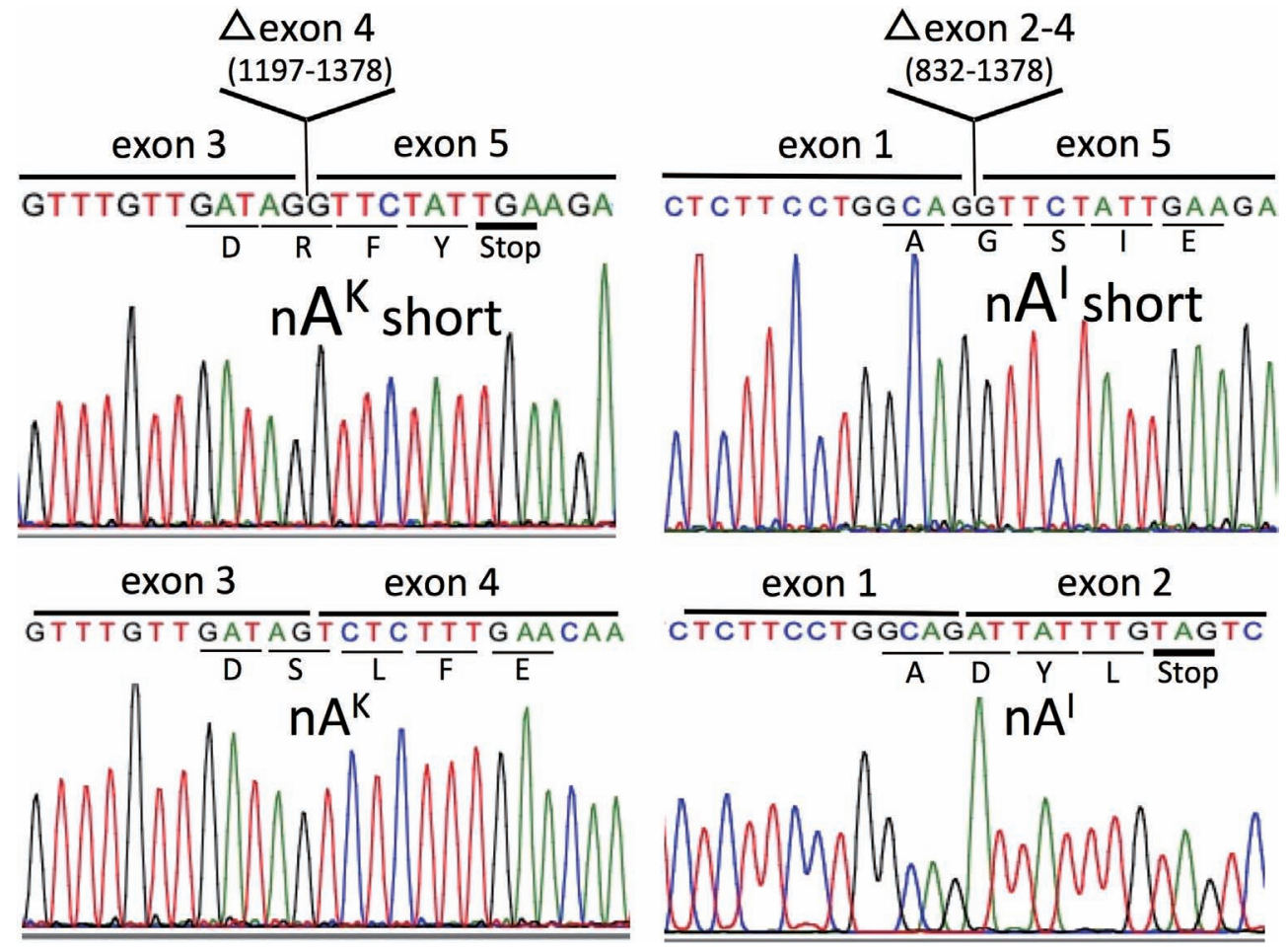

Fig. 4. Nucleotide sequences around the affected exon-intron junctions of two different-sized isoforms of tyrosinase cDNA from albinos of $P$. nigromaculatus. Letters under the bases indicate amino acids encoded by the underlined triplets. $\quad \mathrm{nA}$, albino of $P$. nigromaculatus. Other abbreviations are the same as in Fig. 1.
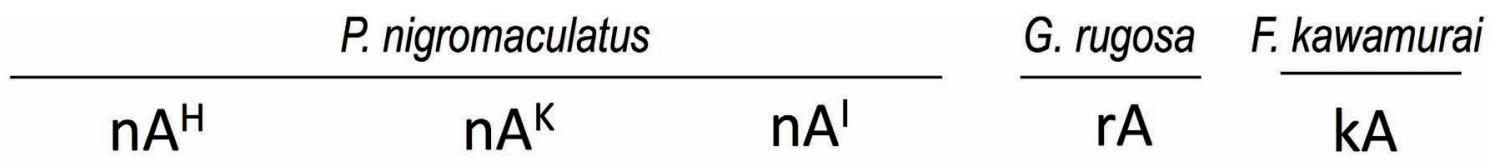

del AAG 682_684 ins T 1244_1245 ins T 768_769
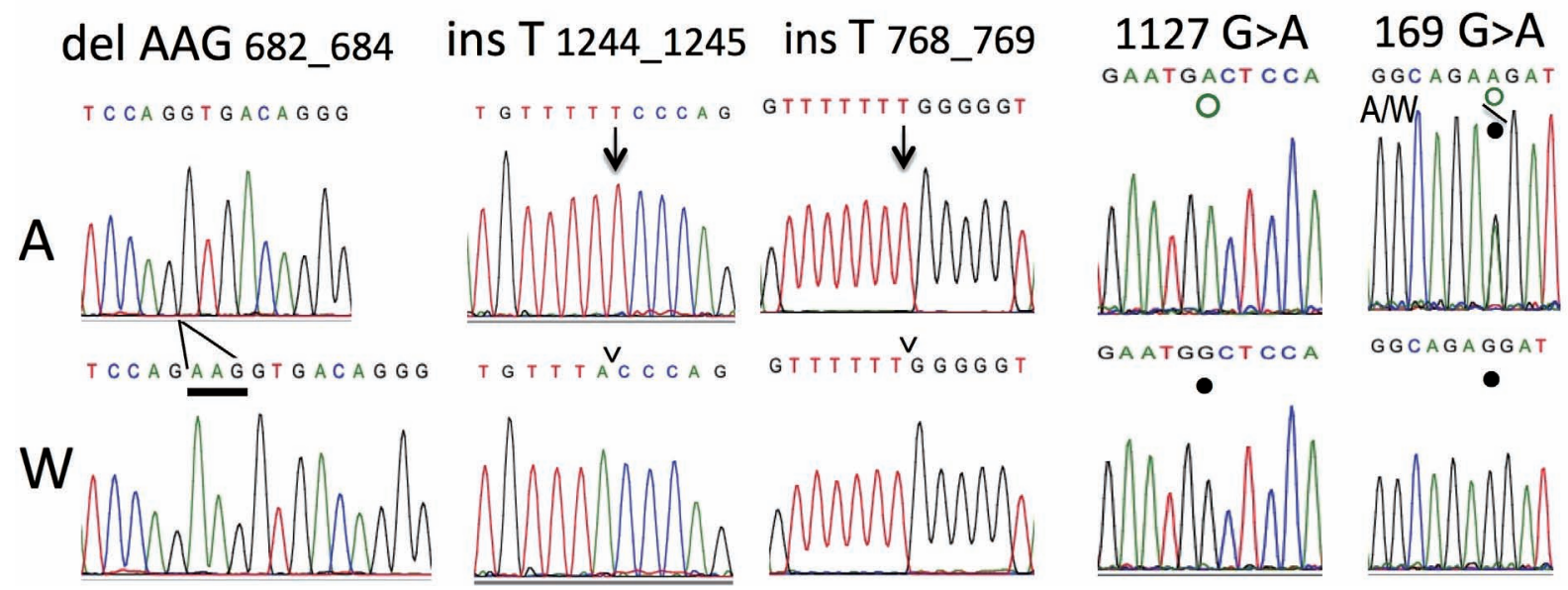

Fig. 5. Nucleotide differences in the tyrosinase genes of wild-type and albino frogs of three species. Abbreviations are the same as in Figs. 1 and 4. Arrows and circles indicate thymine insertions and base substitutions (from closed to open), respectively. The deleted $\mathrm{AAG}$ in $\mathrm{nA}^{\mathrm{H}}$ is underlined. In F. kawamurai, a heterozygous frog was used for sequence analysis. rA, albino of G. rugosa. kA, albino of F. kawamurai. 
were detected on the PstI-digested genomic DNA, of which two corresponded to exons 2 and 3 (Fig. 2). These results indicated that frog tyrosinase comprised five exons.

Identification of tyrosinase mutations in albinos Tyrosinase cDNA fragments from wild-type and albinic frogs were amplified from +1 to +1687 (including the whole coding region of 532 amino acids) in $P$. nigromaculatus and $G$. rugosa and from +123 to +1551 (amino acids 42-516) in F. kawamurai (Figs. 2 and 3). Interestingly, two different-sized bands were amplified simultaneously from each of the two $P$. nigromaculatus albinos $\left(\mathrm{A}^{\mathrm{K}}\right.$ and $\left.\mathrm{A}^{\mathrm{I}}\right)$ examined, one of which corresponded to the predicted normal-sized band, while the other was markedly shorter. Sequence analysis revealed that the shorter isoforms of $\mathrm{A}^{\mathrm{K}}$ and $\mathrm{A}^{\mathrm{I}}$ lacked the entirety of exon 4 and exons 2-4, respectively (Fig. 4).

To identify mutations in the tyrosinase genes of albinic frogs, the entire sequences of normal-sized cDNA fragments were first determined. Three nucleotides, AAG (+682-684), encoding lysine had been deleted in the albino $\mathrm{A}^{\mathrm{H}}$ of P. nigromaculatus (Fig. 5). A thymine had been inserted in exon 4 between +1244 and +1245 and in exon 1 between +768 and +769 in $\mathrm{A}^{\mathrm{K}}$ and $\mathrm{A}^{\mathrm{I}}$, respectively (Fig. 5). In addition, a 29-base deletion between +1350 and +1378 was identified in exon 4 of $\mathrm{A}^{\mathrm{I}}$ (Fig. 6). In albinos of G. rugosa and F. kawamurai, guanines at +1127 in exon 3 and +169 in exon 1 , each of them in a gly-

\begin{tabular}{|c|c|c|c|}
\hline & $\underbrace{\stackrel{n}{n}}_{\text {nn }}$ & $\begin{array}{l}\underset{J}{J} \\
\underset{\sim}{\sim} \\
\underset{N}{ }\end{array}$ & $\begin{array}{l}\widetilde{N} \\
m \\
\frac{n}{m}\end{array}$ \\
\hline Rice frog $(\mathrm{kW})$ & G & K & G \\
\hline Rice frog (kA) & $\mathrm{R}$ & K & G \\
\hline Wrinkled frog (rW) & G & $\mathrm{K}$ & G \\
\hline Wrinkled frog $(r A)$ & G & K & D \\
\hline Pond frog $(\mathrm{nW})$ & $\mathbf{G}$ & K & G \\
\hline Pond frog $\left(n A^{H}\right)$ & G & 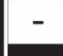 & G \\
\hline Human & G & $\mathrm{K}$ & $c$ \\
\hline Mouse & G & $\mathrm{E}$ & G \\
\hline Chicken & G & $\mathrm{K}$ & G \\
\hline Turtle & G & K & G \\
\hline Clawed frog & G & K & \\
\hline Medaka fish & G & K & \\
\hline
\end{tabular}

Fig. 7. Substituted amino acids of tyrosinase in albino frogs and corresponding amino acids in other vertebrate species. Each of the three amino acids is highly conserved in vertebrates. Amino acid numbers for human tyrosinase are indicated in parentheses. The amino acid sequences of vertebrate tyrosinases are deposited in databases under the accession numbers AAB60319 (human), BAA00341 (mouse), BAA13590 (chicken), XP_006118436.1 (turtle), NP_001096518 (clawed frog) and BAA06155 (medaka).

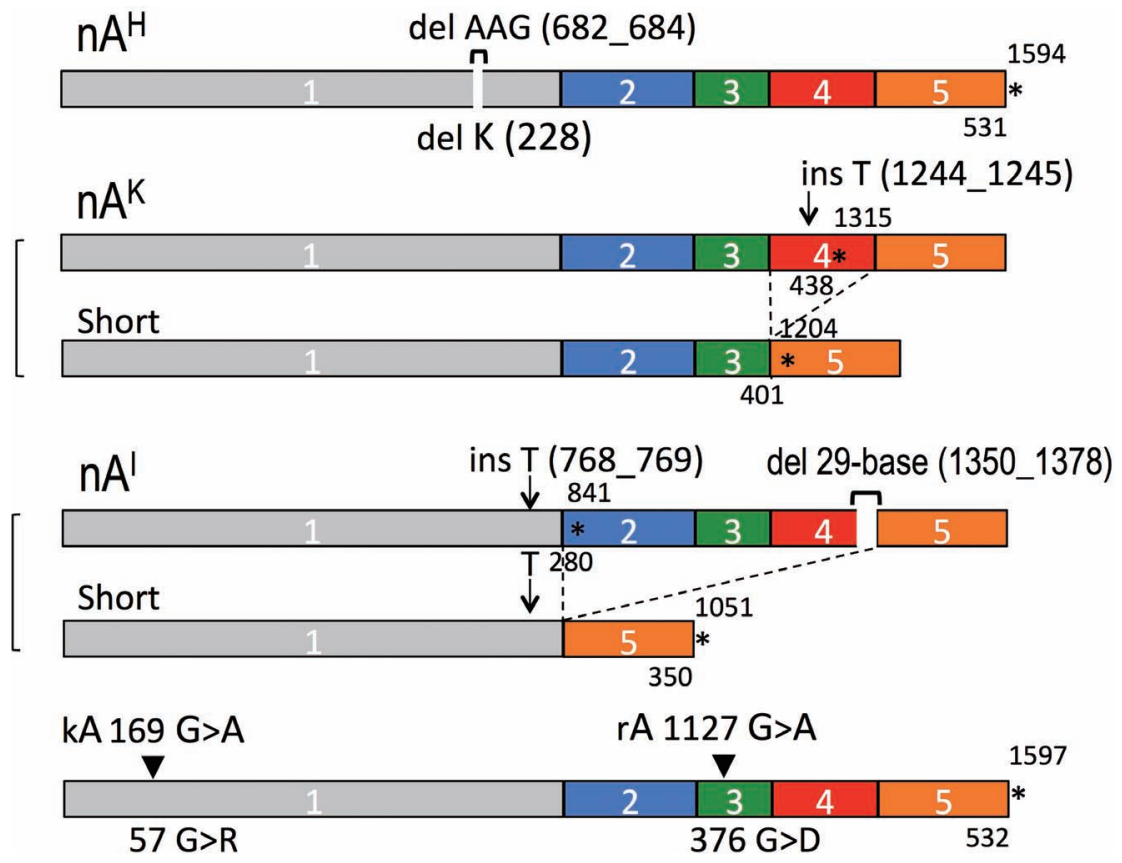

Fig. 6. Schematic representation of tyrosinase mutations in the albinos of three frog species. Arrows, arrowheads and gaps indicate base insertions, substitutions and deletions, respectively. Dashed lines indicate exon(s) deleted in the short isoforms of $\mathrm{nA}^{\mathrm{K}}$ and $\mathrm{nA}$. The number of the first base of the stop codons and number of the length of amino acids are shown above and below the exon structure, respectively. Asterisks indicate stop codons. Abbreviations are the same as in Figs. 1, 4 and 5. 
cine codon, were substituted for adenines, changing the codons to aspartic acid and arginine, respectively (Figs. 5 and 6). These sequence mutations were all confirmed in the corresponding positions of the genomic DNA, with the exception of the 29-base deletion in $\mathrm{A}^{\mathrm{I}}$, which was therefore determined to be an isoform variation lacking 29 bases in exon 4 . The other missense mutations identified in the tyrosinase cDNAs of albino frogs in comparison to wild-type frogs of the same species and to other vertebrate species are listed in Supplementary Table S1.

\section{DISCUSSION}

In the present study, five tyrosinase mutations were identified in the albinos of three Japanese wild frog species (summarized in Fig. 6). It was predicted that all the identified mutations produced dysfunctional tyrosinase proteins because they result in frameshift of translation, deletion or replacement of highly conserved amino acids in vertebrates and therefore might have been responsible for the observed albinic phenotypes. The other missense mutations (listed in Supplementary Table S1) might not have been responsible for the observed albinic phenotypes, since the original amino acids exhibited variability in frogs and vertebrates. Tyrosinase genes in $P$. nigromaculatus $\mathrm{A}^{\mathrm{K}}$ and $\mathrm{A}^{\mathrm{I}}$ produced truncated proteins due to $\mathrm{T}$ insertions within the coding exons, which shifted the reading frames to produce stop codons within exons 4 and 2, respectively (Fig. 6). The shorter mRNA isoforms identified would probably also have produced dysfunctional, truncated proteins since they lacked one or more exons. Deletion of lysine in $\mathrm{A}^{\mathrm{H}}$ and glycine substitutions to aspartic acid and arginine in albinos of G. rugosa and F. kawamurai, respectively, may have also resulted in dysfunctional tyrosinase, since the three original amino acids were highly conserved in vertebrates, suggesting that they are in regions of critical importance to tyrosinase function (Fig. 7). Indeed, the glycine of G. rugosa is located inside in the predicted second copper-binding domain. Gly57 and Gly376 are perfectly conserved in vertebrates, while Lys228 deleted in $\mathrm{A}^{\mathrm{H}}$ differs only in mice, where it is glutamic acid. This $\mathrm{A}^{\mathrm{H}}$ albino strain belongs to Group I (Nishioka and Ueda, 1985), whose members showed no tyrosinase activity during DOPA reaction testing. The locus in this group was located on chromosome 2 (Nishioka et al., 1987), and we have mapped the tyrosinase gene on chromosome 2 by in situ hybridization (unpublished data). Therefore, it is likely that the deletion of Lys228 of tyrosinase is responsible for the observed albinic phenotype in $\mathrm{A}^{\mathrm{H}} P$. nigromaculatus.

Another notable aspect of the mutations identified in albino frogs was the presence of a shorter, extra mRNA isoform that lacked one or more exons. In $\mathrm{A}^{\mathrm{I}}$ and $\mathrm{A}^{\mathrm{K}}$, only one base thymine was inserted in exons 1 and 4 , respectively, while exons $2-4$ or a part of exon 4 in $\mathrm{A}^{\mathrm{I}}$ and exon 4 in $\mathrm{A}^{\mathrm{K}}$ were skipped during splicing. If a thymine insertion was indeed the cause of this alternative splicing, some sequence element that controls splicing position may exist in the coding regions of the exons. Another possibility for alternative splicing is related to nonsensemediated mRNA decay (Baker and Parker, 2004). The skipped (deleted) exons include a premature stop codon: exon 4 in $\mathrm{A}^{\mathrm{K}}$ albinos, and exon 2 in $\mathrm{A}^{\mathrm{I}}$ where exons 2-4 are deleted. It is possible that exon deletion by alternative splicing occurs in association with nonsense-mediated mRNA decay. These hypotheses should be examined through functional analysis using genome editing and extensive sequencing of the regions that harbor the exon/ intron junctions.

The five mutations identified in the albino frogs examined were compared against the list of mutations in the tyrosinase gene in humans and no identical mutations were found; however, substitution of Gly376 to aspartic acid in G. rugosa was similar to a mutation seen in human tyrosinase, in which Gly372 in the second copper-binding domain of an eastern Indian OCA patient, corresponding to Gly376 in frogs, was changed to arginine (Chaki et al., 2006). These results indicate that the mutations that are associated with albinism in the frog species examined are unique among the vertebrates; therefore, we conclude that molecular analysis of albino frogs should contribute to research on albinism by providing new information about the molecular features of tyrosinase and its transcript processing that are unknown in research on humans.

The second question examined in the present study was whether or not the origins of the tyrosinase mutations associated with albinism were the same in different populations of the same frog species. Our results indicated that the origin of the mutations that are associated with albinism depended on the population from which a specimen was obtained, which suggests that these mutations occurred independently in each population. The single-base insertion of thymine and its association with a shorter, extra mRNA isoform that lacked exon(s) was commonly observed in albinos originating from two distant localities, Kumamoto and Ichinomiya. It is possible that species specificity exists in the mechanism by which mutations that are responsible for albinism in frogs are generated. More data will be required to determine the validity of our second hypothesis.

We would like to thank Kikuo Matsumi, Yoshiharu Takeyasu and Manji Yamamoto for collecting and providing us with the wild-caught frog albinos examined in the present study, and Toshitada Higaki for taking a picture of the $\mathrm{A}^{\mathrm{H}}$ albino of $P$. nigromaculatus.

\section{REFERENCES}

Bagnara, J. T., Taylor, J. D., and Hadley, M. E. (1968) The dermal 
chromatophore unit. J. Cell Biol. 38, 67-79.

Baker, K. E., and Parker, R. (2004) Nonsense-mediated mRNA decay: terminating erroneous gene expression. Curr. Opin. Cell Biol. 16, 293-299.

Chaki, M., Sengupta, M., Mukhopadhyay, A., Subba Rao, I., Majumder, P. P., Das, M., Samanta, S., and Ray, K. (2006) OCA1 in different ethnic groups of India is primarily due to founder mutations in the tyrosinase gene. Ann. Hum. Genet. 70, 623-630.

Giebel, L. B., Strunk, K. M., and Spritz, R. A. (1991) Organization and nucleotide sequences of the human tyrosinase gene and a truncated tyrosinase-related segment. Genomics $\mathbf{9}$, $435-445$.

Inagaki, H., Koga, A., Bessho, Y., and Hori, H. (1998) The tyrosinase gene from medakafish: transgenic expression rescues albino mutation. Pigment Cell Res. 11, 283-290.

Kwon, B. S., Haq, A. K., Pomerantz, S. H., and Halaban, R. (1987) Isolation and sequence of a cDNA clone for human tyrosinase that maps at the mouse c-albino locus. Proc. Natl. Acad. Sci. USA 84, 7473-7477.

Miura, I. (2009) The genetic mechanisms of color expression in frogs. Bulletin of the Herpetological Society of Japan 2009, 151-160.

Miura, I., Ohtani, H., Nakamura, M., Ichikawa, Y., and Saitoh, K. (1998) The origin and differentiation of the heteromorphic sex chromosomes $\mathrm{Z}, \mathrm{W}, \mathrm{X}$ and $\mathrm{Y}$ of the frog Rana rugosa, inferred from the sequences of a sex-linked gene, ADP/ATP translocase. Mol. Biol. Evol. 15, 1612-1619.

Miura, I., Okumoto, H., Makino, K., Nakata, A., and Nishioka, M. (1995) Analysis of the tyrosinase gene of the Japanese pond frog, Rana nigromaculata: Cloning and nucelotide sequence of the genomic DNA containing the tyrosinase gene and its flanking regions. Jpn. J. Genet. 70, 79-92.

Müller, G., Ruppert, S., Schmid, E., and Schütz, G. (1988) Functional analysis of alternatively spliced tyrosinase gene transcripts. EMBO J. 7, 2723-2730.

Nishioka, M., and Ueda, H. (1985) Genetics and morphology of 13 albino stocks in the Rana nigromaculata group. Sci. Rep. Lab. Amphibian Biol. 7, 1-121.

Nishioka, M., Ohtani, H., and Sumida, M. (1987) Chromosomes and the sites of five albino gene loci in the Rana nigromaculata group. Sci. Rep. Lab. Amphibian Biol. 9, $1-52$.

Ruppert, S., Müller, G., Kwon, B., and Schütz, G. (1988) Multiple transcripts of the mouse tyrosinase gene are generated by alternative splicing. EMBO J. 7, 2715-2722.

Takase, M., Miura, I., Nakata, A., Takeuchi, T., and Nishioka, M. (1992) Cloning and sequencing of the cDNA encoding tyrosinase of the Japanese pond frog, Rana nigromaculata. Gene 121, 359-363.

Teraoka, S. (2013) Occurrence of the albino mutation of tadpoles of the frog, Rana ornativentris Werner, 1903 from Izumoshi, Shimane Prefecture, Japan. Bulletin of the Hoshizaki Green Foundation 16, 215-217.

Teraoka, S., and Yamaguchi, K. (2009) List of albino and variant individuals of wild anura collected in Shimane Prefecture. Bulletin of the Hoshizaki Green Foundation 12, 221-227.

Yamamoto, H., Takeuchi, S., Kudo, T., Makino, K., Nakata, A., Shinoda, T., and Takeuchi, T. (1987) Cloning and sequencing of mouse tyrosinase cDNA. Jpn. J. Genet. 62, 271-274. 